\title{
Rice: The First Crop Genome
}

Scott A. Jackson

\begin{abstract}
Rice was the first sequenced crop genome, paving the way for the sequencing of additional and more complicated crop genomes. The impact that the genome sequence made on rice genetics and breeding research was immediate, as evidence by citations and DNA marker use. The impact on other crop genomes was evident too, particularly for those within the grass family. As we celebrate 10 years since the completion of the rice genome sequence, we look forward to new empowering tool sets that will further revolutionize research in rice genetics and breeding and result in varieties that will continue to feed a growing population.
\end{abstract}

Keywords: Rice, Genome Sequencing, Translation, Gene Mapping

\section{Introduction and Review: Rice as a Model Genome The Rice Genome}

The rice genome was one of the few truly multinational plant genome projects, one with flags planted in chromosomes (Eckardt 2000)-Japan, chromosomes 1, 6, 7 \& 8; US, chromosomes 3 \& 10; China, chromosome 4; France, chromosome 12; Taiwan, chromosome 5; etc.like early explorers claiming new territories. Arabidopsis had been sequenced and published in 2000 (Arabidopsis Genome I 2000) and rice, nearly four times the size, was next. These were heady days for plant genome researchers, a discipline still in its infancy. Researchers jockeyed to be part of the project and, like every good collaborative project, multitudinous meetings were held to plan, to execute and, finally, to celebrate the rice genome project. These meetings were often tensedeciding how chromosomes were distributed, discussing progress, or lack thereof-and the omnipresent funding agency representatives hovered about ensuring that their agencies funds were well spent, the most diminutive of whom could elicit fear in the most seasoned genome researcher.

Rice was one of the last clone-by-clone, Sangersequenced genomes. That is, BAC/PAC clones were sequentially selected for sequencing, independently assembled and then stitched together to form pseudochromosomes. One impact that the rice genome had, even in the midst of sequencing, was the first completely

Correspondence: sjackson@uga.edu

Center for Applied Genetic Technologies, University of Georgia, Athens, GA 30621, USA sequenced, complex eukaryotic centromere on chromosome 8 (Nagaki et al. 2004), which are usually gaps in genome sequences as they are highly repetitive regions of the genome. This was possible due to its diminutive size, $\sim 64 \mathrm{kbp}$ of satellite repeats, even compared to even Arabidopsis centromeres. Thus, rice has been a model for studies of centromere structure and function. This was possible due to cytogenetic analysis of rice showing the diminutive centromere 8 . Interestingly, if the US had heeded cytogenetic descriptions they may not have chosen chromosome 9 as a sequencing target as one arm is highly heterochromatic, full of repetitive DNA sequences, which complicated physical mapping and sequencing of that chromosome arm.

The public rice genome, which took advantage of whole genome shotgun sequenced genomes made available from Monsanto in 2000 and Syngenta in 2002 (Goff et al. 2002), was published in 2006 (International Rice Genome Sequencing P 2005) after which the arduous task of annotation took place. Rice was one of the few genomes to have competing annotations (Ohyanagi et al. 2006; Ouyang et al. 2007), which created some confusion in the community but was eventually resolved with a single unified annotation (Kawahara et al. 2013).

\section{Rice as a Model Cereal Genome}

One of the initial motivators for sequencing rice, besides the relatively small genome size, was that it could be used as a model for other cereal crops with larger genomes, such as maize and wheat. This was predicated somewhat on rice's small genome size and the realization 
from molecular mapping, e.g. RFLPs, of conserved markers and marker order. Early work had shown conserved synteny between sorghum and maize (Hulbert et al. 1990) and subsequent work had shown conserved synteny over even longer evolutionary timeframes leading to the model of concentric circle genomes based on conserved marker order among a number grasses (Moore et al. 1995).

Even though considerable genetic synteny was found in comparisons of other cereals to rice, sequencing of orthologous genomic regions uncovered considerable variation, in gene content, repeat structure and size. One of the first comparisons of rice, maize and sorghum, preceding the rice genome sequencing project, revealed extensive size variation, especially inflated in maize, and in conservation of low copy sequences among the three species (Chen et al. 1997). Subsequent studies have shown that while rice is generally predictive of gene content in related cereal genomes, many genes are missed as either absent in rice, or present in rice and absent in the comparator. For instance in a rice-barley comparison around a disease resistance locus, barley had six additional genes not found in the rice orthologous region (Moore et al. 1995). Thus, while useful for leveraging genetics in other cereal species, additional crop genome sequences were required to fully address the genetic underpinning of traits in those crops.

\section{Contribution to Advancement of Rice Genetics and Improvement \\ Gene and QTL Cloning}

Gene cloning and especially cloning genes underlying QTL can provide a deeper molecular understanding of a trait and in the case of breeding, markers linked directly with the causative DNA mutation/changes. In rice, from
1990 to 1994 there were $20-30$ papers per year retrieved by using 'gene cloning' as a search term (Fig. 1). In 1995, the first rice BAC library was published (Wang et al. 1995) which was eventually used for cloning of the Xa-21 resistance gene (Song et al. 1995). Between 1995 and 2001, as more cloning tools became available, the number per year ranged in the 40-80. After the genome sequence, the number jumped to more than 100 per year and has been fairly stable since. Even though this analysis is very rough, no manual curation of the extracted references, just a count of returned citations, it seems obvious that the genomic resources of large insert DNA clones and eventually the genome sequence greatly advanced gene/ QTL cloning in rice. An obvious example of where the genome facilitated cloning of a gene underlying a QTL is $S U B 1$, the gene that confers subermergence tolerance $(\mathrm{Xu}$ et al. 2006). Another outgrowth of the reference genome is the exploration of diversity at a genome scale across the entire Oryza genus (Ammiraju et al. 2008; Lu et al. 2009; Sanyal et al. 2010; Jacquemin et al. 2014), including exploration within relatives closely related to cultivated rice (AA genome species) (Wang et al. 2014; Zhang et al. 2014). Many of these explorations depended on resources that arose from the International Oryza Map Alignment Project (Wing et al. 2005; Ammiraju et al. 2006).

\section{Contribution of the Rice Genome to Improvement}

The bigger goal for the community is rice improvement. On several fronts the rice reference genome has greatly advance rice improvement. First, the most immediate impact was in molecular markers in that the number was greatly increased, their physical order was understood and proximity to annotated genes was useful to predict gene-trait associations. In part, this has been

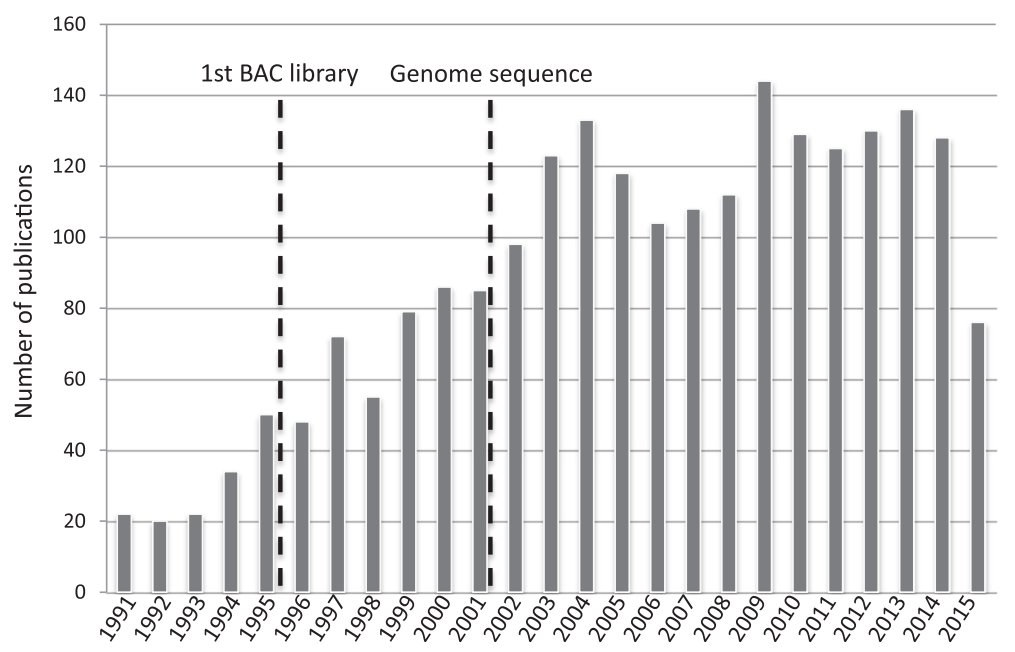

Fig. 1 Publications related to gene cloning in rice. ISI Web of Science (26-August-2015): search 'rice' and 'gene cloning' 1990-2015, retrieved 2,237 records 
driven by reduction in DNA sequencing costs that have allowed researchers to resequence additional rice accessions and call nucleotide variations relative to the reference genome (McNally et al. 2009). Second, and related to the first, in-depth, sequence-based analysis of variation in cultivated and wild rice to allow breeders to better understand and exploit genetic variation, as proposed by McCouch and colleagues (McCouch et al. 2012). Third, molecular understanding of the genetic basis of traits such as $\mathrm{N}$ and P-use is allowing rice researchers to engineer 'Green Super Rice' that should help meet the challenge of the growing world population while requiring fewer inputs (Zhang 2007).

\section{Conclusions}

The availability of the rice genome, together with the community annotation and other resources that added functionality, transformed genetics research and rice breeding. This can be measured any number of ways, but the increase in gene/QTL cloning is one direct measure. Ongoing work to understand the evolution and domestication of rice and to use this and information on the genetic architecture underlying plant physiological responses and phenotypes is now be used to engineer superior rice strains to feed our growing population.

\section{Abbreviations}

BAC: bacterial artificial chromosome; bp: base pair; QTL: quantitative trait loci; RFLP: restriction fragment length polymorphisms.

\section{Competing Interests}

The author declares that he has no competing interest.

\section{Author's Contributions}

Written by SAJ.

\section{Acknowledgements}

None.

Received: 17 November 2015 Accepted: 16 March 2016

Published online: 22 March 2016

\section{References}

Ammiraju JS, Luo M, Goicoechea JL, Wang W, Kudrna D, Mueller C, Talag J, Kim H, Sisneros NB, Blackmon B et al (2006) The Oryza bacterial artificial chromosome library resource: construction and analysis of 12 deep-coverage large-insert BAC libraries that represent the 10 genome types of the genus Oryza. Genome Res 16(1):140-147

Ammiraju JS, Lu F, Sanyal A, Yu Y, Song X, Jiang N, Pontaroli AC, Rambo T, Currie J, Collura K et al (2008) Dynamic evolution of oryza genomes is revealed by comparative genomic analysis of a genus-wide vertical data set. Plant Cell 20(12):3191-3209

Arabidopsis Genome I (2000) Analysis of the genome sequence of the flowering plant Arabidopsis thaliana. Nature 408(6814):796-815

Chen M, SanMiguel P, de Oliveira AC, Woo SS, Zhang H, Wing RA, Bennetzen JL (1997) Microcolinearity in sh2-homologous regions of the maize, rice, and sorghum genomes. Proc Natl Acad Sci U S A 94(7):3431-3435

Eckardt NA (2000) Sequencing the rice genome. Plant Cell 12(11):2011-2017

Goff SA, Ricke D, Lan TH, Presting G, Wang R, Dunn M, Glazebrook J, Sessions A, Oeller P, Varma $\mathrm{H}$ et al (2002) A draft sequence of the rice genome (Oryza sativa L. ssp. japonica). Science 296(5565):92-100
Hulbert SH, Richter TE, Axtell JD, Bennetzen JL (1990) Genetic mapping and characterization of sorghum and related crops by means of maize DNA probes. Proc Natl Acad Sci U S A 87(11):4251-4255

International Rice Genome Sequencing P (2005) The map-based sequence of the rice genome. Nature 436(7052):793-800

Jacquemin J, Ammiraju JS, Haberer G, Billheimer DD, Yu Y, Liu LC, Rivera LF, Mayer K, Chen M, Wing RA (2014) Fifteen million years of evolution in the Oryza genus shows extensive gene family expansion. Mol Plant 7(4):642-656

Kawahara Y, de la Bastide M, Hamilton JP, Kanamori H, McCombie WR, Ouyang S, Schwartz DC, Tanaka T, Wu J, Zhou S et al (2013) Improvement of the Oryza sativa Nipponbare reference genome using next generation sequence and optical map data. Rice 6(1):4

Lu F, Ammiraju JS, Sanyal A, Zhang S, Song R, Chen J, Li G, Sui Y, Song X, Cheng $Z$ et al (2009) Comparative sequence analysis of MONOCULM1orthologous regions in 14 Oryza genomes. Proc Natl Acad Sci U S A 106(6):2071-2076

McCouch SR, McNally KL, Wang W, Sackville HR (2012) Genomics of gene banks: A case study in rice. Am J Bot 99(2):407-423

McNally KL, Childs KL, Bohnert R, Davidson RM, Zhao K, Ulat VJ, Zeller G, Clark RM, Hoen DR, Bureau TE et al (2009) Genomewide SNP variation reveals relationships among landraces and modern varieties of rice. Proc Natl Acad Sci U S A 106(30):12273-12278

Moore G, Devos KM, Wang Z, Gale MD (1995) Cereal genome evolution. Grasses, line up and form a circle. Curr Biol 5(7):737-739

Nagaki K, Cheng Z, Ouyang S, Talbert PB, Kim M, Jones KM, Henikoff S, Buell CR, Jiang J (2004) Sequencing of a rice centromere uncovers active genes. Nat Genet 36(2):138-145

Ohyanagi H, Tanaka T, Sakai H, Shigemoto $Y$, Yamaguchi K, Habara T, Fujii $Y$, Antonio BA, Nagamura Y, Imanishi T et al (2006) The Rice Annotation Project Database (RAP-DB): hub for Oryza sativa ssp. japonica genome information. Nucleic Acids Res 34:D741-744

Ouyang S, Zhu W, Hamilton J, Lin H, Campbell M, Childs K, Thibaud-Nissen F, Malek RL, Lee $Y$, Zheng L et al (2007) The TIGR Rice Genome Annotation Resource: improvements and new features. Nucleic Acids Res 35:D883-887

Sanyal A, Ammiraju JS, Lu F, Yu Y, Rambo T, Currie J, Kollura K, Kim HR, Chen J, Ma J et al (2010) Orthologous comparisons of the Hd1 region across genera reveal $\mathrm{Hd} 1$ gene lability within diploid Oryza species and disruptions to microsynteny in Sorghum. Mol Biol Evol 27(11):2487-2506

Song WY, Wang GL, Chen LL, Kim HS, Pi LY, Holsten T, Gardner J, Wang B, Zhai WX, Zhu LH et al (1995) A receptor kinase-like protein encoded by the rice disease resistance gene, Xa21. Science 270(5243):1804-1806

Wang GL, Holsten TE, Song WY, Wang HP, Ronald PC (1995) Construction of a rice bacterial artificial chromosome library and identification of clones linked to the Xa-21 disease resistance locus. Plant J 7(3):525-533

Wang M, Yu Y, Haberer G, Marri PR, Fan C, Goicoechea JL, Zuccolo A, Song X, Kudrna D, Ammiraju JS et al (2014) The genome sequence of African rice (Oryza glaberrima) and evidence for independent domestication. Nat Genet 46(9):982-988

Wing RA, Ammiraju JS, Luo M, Kim H, Yu Y, Kudrna D, Goicoechea JL, Wang W, Nelson W, Rao K et al (2005) The oryza map alignment project: the golden path to unlocking the genetic potential of wild rice species. Plant Mol Biol 59(1):53-62

Xu K, Xu X, Fukao T, Canlas P, Maghirang-Rodriguez R, Heuer S, Ismail AM, Bailey-Serres J, Ronald PC, Mackill DJ (2006) Sub1A is an ethyleneresponse-factor-like gene that confers submergence tolerance to rice. Nature 442(7103):705-708

Zhang Q (2007) Strategies for developing Green Super Rice. Proc Natl Acad Sci U S A 104(42):16402-16409

Zhang QJ, Zhu T, Xia EH, Shi C, Liu YL, Zhang Y, Liu Y, Jiang WK, Zhao YJ, Mao SY et al (2014) Rapid diversification of five Oryza AA genomes associated with rice adaptation. Proc Natl Acad Sci U S A 111(46):E4954-4962 